\title{
Paleoimagen y análisis bioantropológico de la colección Maranga del Museo Jacinto Jijón y Caamaño
}

\author{
Maria Patricia Ordoñez, Dr. Ronald Beckett, Dr. Andrew Nelson, Dr. Gerald Conlogue*
}

RESUMEN

Este artículo recoge los resultados de los estudios de Paleoimagen y análisis Bioantropológicos REALIZAdOS EN 38 FARdOS FUNERARIOS, PARTE DE LA COLECCIÓN DE RESTOS HUMANOS PERUANOS QUE SE ENCUENTRA en el Museo Jacinto Jijón y Caamaño, en el Centro Cultural de la PUCE. La investigación realizada en EL 2013 SE CENTRÓ EN TRES TEMAS: CONSERVACIÓN DE LOS FARDOS, DESCRIPCIÓN DE LOS INDIVIDUOS Y COMPOSICIÓN DE LOS FARDOS, CON MIRAS A INTERPRETAR DATOS POBLACIONALES ANTES DESCONOCIDOS.

EL PROYECTO PRESENTADO EN ESTE ARTíCULO ES EL PRIMERO DE SU CLASE REALIZADO EN ESTA COLECCIÓN, SE RESALTA POR TANTO TAMBiÉn LA IMPORTANCIA Y EL ÉXITO DE La COLABORACIÓN ENTRE UNA INSTITUCIÓN COMO EL MUSEO JaCinTo JiJón y CAAMAÑo Y UN GRUPO dE INVESTIGAdORES ESPECIALISTAS.

Palabras Clave: Maranga - Paleoimagen - momias - Jacinto Jijón y Caamaño.

Abstract

This article includes the results of Paleo-image studies and Bioanthropological analysis of 38 funerary bundles that are part of the collection of Peruvian human remains found in the Museum Jacinto JiJón y Caamaño at the Cultural Center of the PUCE. 2013 research focused on three themes: conservation OF THE BUNDLES, DESCRIPTION OF INDIVIDUALS AND COMPOSITION OF THE BUNDLES, AIMING TO INTERPRET PREVIOUSLY UNKNOWN POPULATION DATA.

THE PROJECT PRESENTED IN THIS ARTICLE IS THE FIRST OF ITS KIND IN THIS COLLECTION, HIGHLIGHING THE IMPORTANCE of the success of the collaboration between an institution such as the Museum Jacinto Jijón y Caamaño AND A GROUP OF RESEARCHERS SPECIALISTS.

Keywords: Maranga - Paleo-image - funerary bundles - Jacinto Jijón y CaAmaño.

* Maria Patricia Ordoñez (Leiden University) mpordonezalvarez@yahoo.com, Dr. Ronald Beckett (Quinnipiac University), Dr. Andrew Nelson (University Western Ontario), Dr. Gerald Conlogue (Quinnipiac University). 


\section{Introducción}

$\mathrm{E}$ n este artículo se presentan los resultados de los estudios de Paleoimagen y análisis Bioantropológicos realizados en 38 fardos funerarios parte de la colección de restos humanos peruanos que se encuentra en el Museo Jacinto Jijón y Caamaño, en el Centro Cultural de la PUCE. El estudio se llevó a cabo en Quito del 13 al 18 de enero del 2013 y del 31 de Mayo al 1 de Junio del 2013. Los fardos investigados forman parte de la colección inicialmente excavada por Jijón y Caamaño en 1925 en el complejo arqueológico Maranga, ubicado en la región del río Rímac, hoy en día el centro moderno de Lima. De los 38 fardos examinados, únicamente 33 contuvieron restos humanos. Si bien la colección en total está catalogada como perteneciente a Maranga, algunos textiles y la forma de construcción de los fardos permiten identificar rasgos culturales más puntuales.

El proyecto presentado en este artículo es el primero de su clase realizado en esta colección y permitió no solo entender la composición de los fardos si no presentar datos poblacionales antes desconocidos respecto a la colección. Este informe resalta la importancia y el éxito de la colaboración entre una institución como el Museo Jacinto Jijón y Caamaño y un grupo de investigadores especialistas.

\section{Antecedentes}

El complejo arqueológico Maranga, asociado a las culturas Lima (100-650 d.C.) e Ichma (900-1470 d.C.) está constituido por una serie de restos monumentales en la región del río Rímac (Eeckhout, 2004). El complejo está formado por grandes Huacas (montículos artificiales) construidas en un estilo 'estantería', llamado así por que los ladrillos (aboditos) de las paredes aparecen como libros en un estante. La expansión y construcción de dichas estructuras continuaron hasta la invasión Inca (Evans, 1956).

En 1925 el ecuatoriano Conde Jacinto Jijón y Caamaño (1890 - 1950), heredero de una de las familias más ricas de Quito, realiza durante su exilio político en Perú, una de las primeras excavaciones científicas en las Hucas San Marcos, Middendorf y Concha del complejo. Jijón excava en manera detallada y manteniendo un registro estratigráfico lúcido cerca de 72 fardos funerarios de entre estas tres estructuras (Jijón y Caamaño, 1949).

Cuarenta y dos de estos fardos fueron devueltos a Quito, transportados vía mula y caballo desde su lugar de origen, para unirse a la creciente colección de piezas arqueológicas en poder de la familia de Jijón. En 1963, la colección de la familia, incluyendo los fardos, fue donada al Centro Cultural de la Pontificia Universidad Católica de Quito, y es entonces cuando se funda el Museo Jacinto Jijón y Caamaño. Desde ese punto en adelante, los fardos han sido conservados en las instalaciones del museo. Han sido inventariados y descritos, sin embargo no han sido explorados de manera continua y organizada antes de este estudio.

Es importante aquí recalcar que si bien la colección no ha sido estudiada a detalle, el museo ha mantenido como una de sus prioridades el inventariar y preservar los restos humanos que forman parte de su colección. Un ejemplo claro de este interés es el inventario descriptivo y detallado de los restos humanos de la colección ecuatoriana realizado en el 2004, y más recientemente la creación de un área climatizada y especializada para el mantenimiento de los restos de las colecciones ecuatoriana y peruana dentro de la nueva infraestructura con la que cuenta el museo en el Centro Cultural de la PUCE y que estuvo en operación antes de su reapertura en Mayo del 2014.

Una prospección para recabar parte de la información aun preservada en estas Huacas del complejo arqueológico Maranga se llevó a cabo en Lima, Perú en diciembre del 2012. Dada la extensa alteración que estas estructuras han atravesado, tanto por la expansión de la ciudad como por las excavaciones múltiples en ellas realizadas, es claro que la colección que se encuentra hoy en el museo Jijón y Caamaño es una de las más completas para el sitio. 


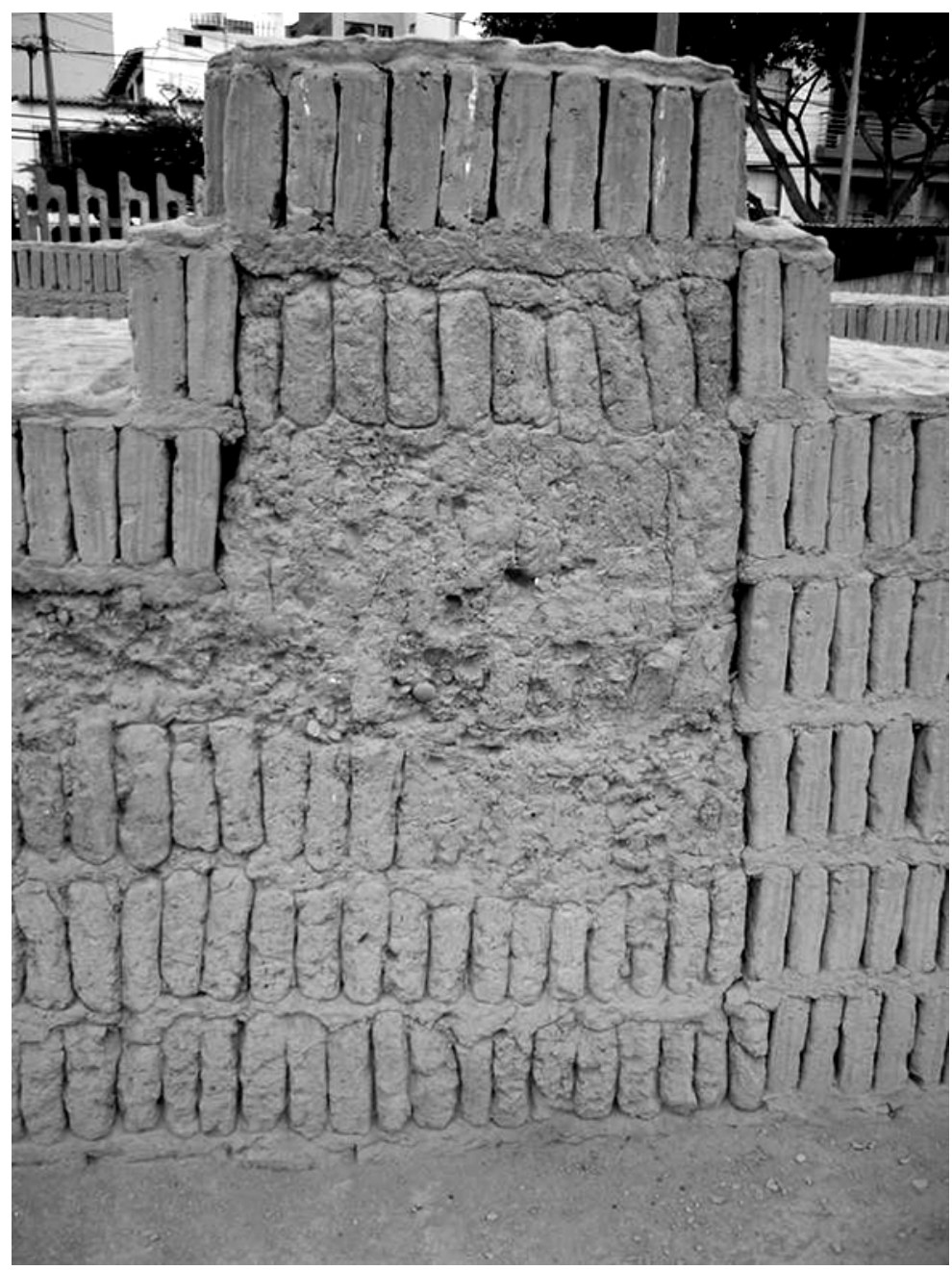

Figura 1. Foto de pared de adobitos, Huaca Pucllana, Lima, Perú. Tomada POR M. ORdoñez, Diciembre de 2012.

Lo que sabemos de la cultura Maranga proviene principalmente de análisis de materiales culturales como cerámica y textiles, mas no de una caracterización detallada de sus fardos funerarios, por lo que la meta principal era poder acrecentar el acervo de datos existente respecto a la colección, y poder compararlo con esos datos arqueológicos ya existentes. Una base comparativa respecto a lo que se conoce desde la arqueología respecto a las prácticas funerarias de las culturas asentadas en Maranga se logra a través de revisión bibliográfica y entrevistas con antropólogos e historiadores regionales en el mismo tiempo.

El principal objetivo de la expedición que recuenta este artículo fue realizar estudios de paleoimagen no destructivos y análisis bioantropológicos de los alrededor de 40 fardos Maranga alojados en el Museo Jacinto Jijón y Caamaño. El apoyo logístico y la apertura para establecer un taller completo de radiología de campo en las instalaciones del Museo permitió un flujo impecable y acceso a investigar a detalle incluso los fardos más delicados de la colección sin afectar su preservación. 


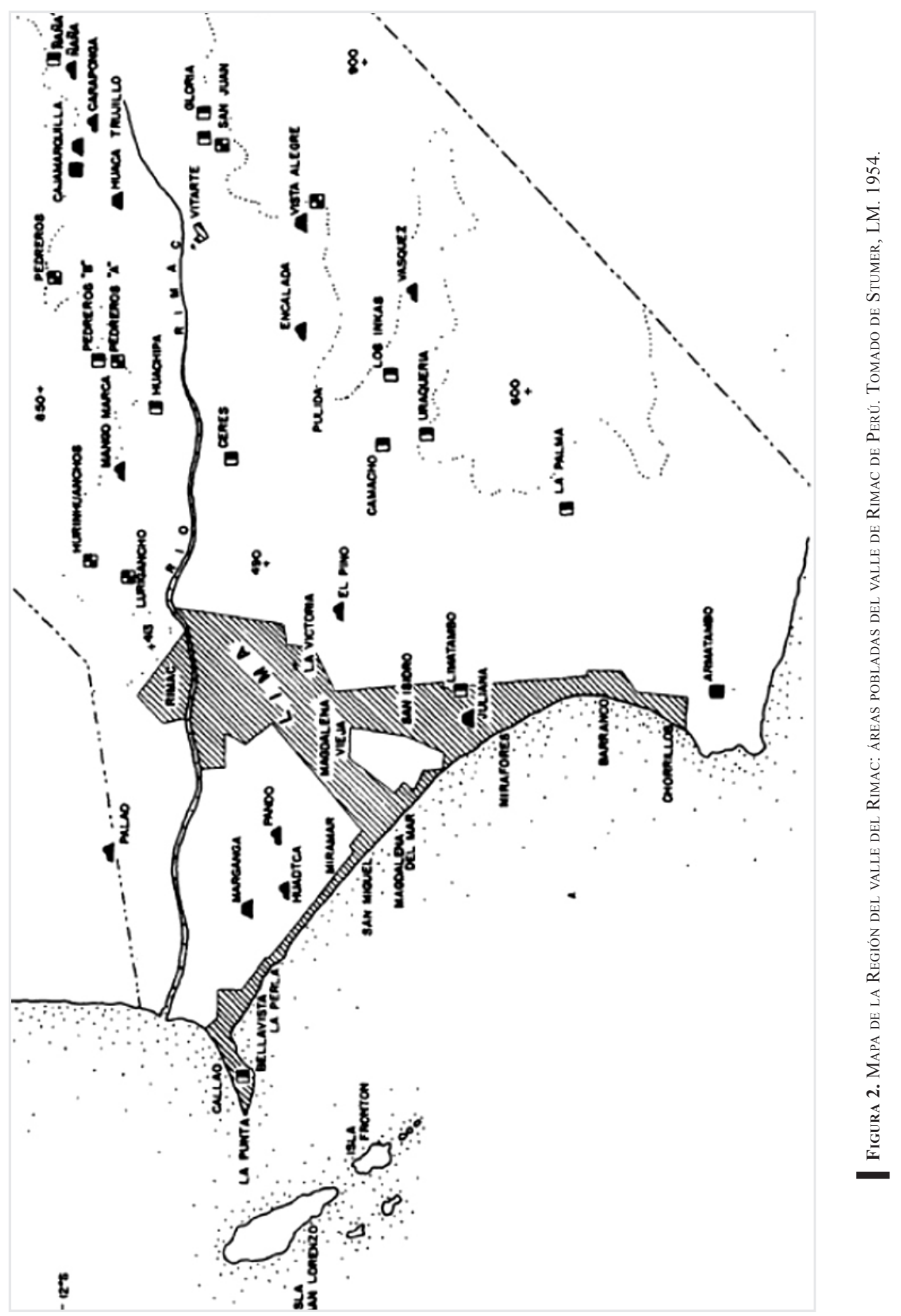


El proyecto de investigación se llevó a cabo en dos fases, la primera a partir de 13 de hasta el 18 de enero de 2013 en Quito y una segunda fase del 31 de Mayo al 1 de Junio del 2014, en el Museo Jacinto Jijón y Caamaño y en el centro AXIS de radiología, respectivamente.

La Fase 1 incluyó el análisis de paleoimagen y examinación de rasgos bioarqueológico de los fardos. Los métodos de paleoimagen incluyen radiografías computarizadas, video- endoscopia, fotografía y videografía. A través de estos análisis se intentó determinar la naturaleza de los contenidos de cada paquete en términos de su estado de conservación, estabilidad y posición general de los restos así como de las características de su contenido, incluyendo: sexo, número de entierros por paquete, edad de los individuos, evidencias de trauma o lesión, evidencia de enfermedad, y la presencia de inclusiones de artefactos que puedan ser usados para interpretar las prácticas funerarias.

Un examen visual macroscópico, junto con la documentación de las características del paquete $\mathrm{y}$, cuando fue posible dada la visibilidad de restos osificados fuera del paquete, la antropometría, fue llevada a cabo dando datos tales como la construcción de fardo, inclusiones, y la presencia de artefactos asociados.

Para la Fase 2, se seleccionaron aquellos fardos funerarios de la Fase 1 que fueron lo suficientemente estables como para moverse, y sobre los que se tenían preguntas adicionales que podrían ser respondidas con proyección de imágenes médicas más avanzadas, en este caso tomografías computarizadas. Los criterios de selección incluyen aspectos tales como la estabilidad, lesiones por enfermedad, y la existencia de artefactos funerarios dentro del fardo.

\section{Materiales y métodos}

Cuatro laboratorios de campo separados, o estaciones, se establecieron en el área de la investigación y las colecciones del museo. La ubicación de los equipos en relación con el cuarto climatizado donde se mantienen los restos fue ideal para mantener un flujo de trabajo adecuado en el área, así como el uso en partes de la colección etnográfica como material de referencia para los hallazgos de rayos x obtenidos con el apoyo de los curadores y responsables del Museo. En este caso se destacan muestras de elementos de metal, maíz, madera y textil. Una estación para el análisis arqueológico/antropométrico, dos para paleoimagen usando radiografía computarizada y video - endoscopia, y otra para la documentación y el registro.

La radiografía computarizada se realizó utilizando un escáner CR Kubscan 3600, un tubo Xtend 100HF X- Ray, junto con las placas de los sensores asociados y equipo. Se utilizaron postes de madera para alcanzar la altura requerida para un SID correcto (fuente a distancia de la imagen). Un soporte para la película se construyó utilizando una hoja delgada de material de madera comprimida con el espacio por debajo para pasar los casetes de película en la médula. De esta manera, los fardos, una vez colocados sobre una radiografía, tenían un movimiento mínimo.

La endoscopia se realizó utilizando dos instrumentos diferentes. Un $6 \mathrm{~mm}$ articulación industrial vídeo -scope Olympus se utilizó en la estación de endoscopia; mientras que un VJ industrias $7 \mathrm{~mm}$ articular vídeo -scope se utilizó para examinar fardos en el sitio de almacenamiento provisional de rayos X y la estación de arqueo/antropometría.

Se utilizó fotografías para documentar las características externas específicas de cada fardo funerario, así como las características técnicas de configuración y operaciones de las estaciones de trabajo en el área designada dentro de la Reserva del Museo Jacinto Jijón y Caamaño.

Las medidas Arqueo/antropométricas se realizaron utilizando instrumentos antropológicos estándar, fotografías, instrumentos de medición como calibradores y flexómetros, una lupa de mano, y siguiendo una metodología de inspección visual detallada.

En la Fase 2, las Tomografías Computarizadas (CT) del subgrupo de cuatro momias se llevaron a cabo en Quito en el centro de radiología del hospital AXXIS, con la ayuda del 
grupo Radiólogos Asociados ubicado en la Av. 10 de Agosto N 39-155 y Diguja en la ciudad de Quito. El acceso a este equipo así como la posibilidad de movilizar los fardos se hizo gracias a la gestión del grupo de profesionales del Museo Jacinto Jijón y Caamaño y permitió no sólo reducir los costos de la investigación si no contar además con un grupo ampliado de especialistas para la discusión y examinación de los restos. El equipo utilizado fue un Philips Brilliant 64 slice scanner. Todos los scans son hechos en modo helical $-512 * 512$ matrix $-0.6 \mathrm{~mm}$ ancho de slice. Se escanean 4 momias: JC-AP 1476; JC-AP 1495; JC-AP 2288; JC-AP 2305.

\section{Conclusiones generales}

Hemos sido capaces de examinar 38 paquetes, 33 de las cuales contenían restos humanos, y varios cráneos no envueltos, durante la primera etapa de investigación. Además, se examinó una extremidad anterior y el cráneo de una especie canina.

A continuación se presenta una descripción general de los resultados que se desprenden junto con varios estudios de casos específicos.

\section{Construcción y contenidos de los fardos}

De acuerdo a la literatura correspondiente un paquete funerario típico para las tradiciones Lima e Ichma está envuelto en varias capas de materia textil, junto con un tipo de varilla de madera o una camilla de caña para la estabilidad (Svendsen, 2010). La examinación de los restos en efecto confirma tal configuración. A menudo, los restos fueron apoyados con algodón y varillas de madera, cuerda y cestas tejidas. Inclusiones funerarias comunes fueron el maíz, metales (probablemente cobre) pendientes y amuletos (en su mayoría deteriorados dejando manchas de metal), perlas, 'almohadas' de algodón, piedras, bobinas de hilo, calabazas de apoyo, conchas, pinzas cortantes metálicas, y en un paquete separado de una momia, un cabestrillo con piedras de honda. En uno de los casos de adultos un tatuaje fue visto en la muñeca izquierda.

Los fardos son en general bastante similares respecto a su construcción, si bien existen algunas variaciones. Aunque temáticamente similares, estas variaciones incluyen: un número inconsistente de los postes de madera o soportes de caña, la presencia de esteras de caña, variadas inclusiones de piedras y semillas, y varios estilos textiles (recuento de capa, la armadura y el patrón). De los paquetes que hemos examinado, cada una contenía un solo individuo, independientemente del tamaño del paquete.

En la Figura 3 presentamos una envoltura típica que demuestra la variedad de textiles empleados:

Momia paquete jc -ac -2068, seis capas diferentes de textiles y estilos están señaladas (T1T6). T1 fue el textil más externo que cubre el cuerpo. T1 fue un tejido suelto con rayas o patrón de tartán 1 x 1 . T2 fue un textil rayado, este se coloca sobre el extremo de la cabeza, se metió debajo del cráneo y se pliega sobre los hombros. T2 era un tejido de 1 x 1 con rayas incluyendo una línea negra, bordes blancos y un núcleo de gama marrón. T3 es un tejido en 1x1, que cubre la mayor parte del cuerpo y no tiene diseño. T4 era un tejido de rayas que cubre la zona de los pies del paquete, pero era diferente de T1 y T2 en este, el color de la tira fue un gran patrón azul, azul, rojo estrecho, largo y ancho. T5 fue un tejido liso 1 x 1, visible por debajo de T3 a través de una ruptura en las capas exteriores. T6 fue único, ya que forma las correas alrededor de la región del hombro, justo por debajo de T2. T6 también tenía un único patrón de rayas marrones estrechas. También estuvieron presentes el embalaje de algodón, cuerdas estrechas, y las cañas planas.

Hay muchas variaciones con respecto a las capas textiles; estas van a partir de dos capas a más de catorce. Hay fardos de tamaño variado, con un rango de $38 \mathrm{~cm}$. x $20 \mathrm{~cm}$. x $16 \mathrm{~cm}$. el más pequeño, a $126 \mathrm{~cm}$. x $54 \mathrm{~cm}$. x $76 \mathrm{~cm}$. el mayor paquete. 

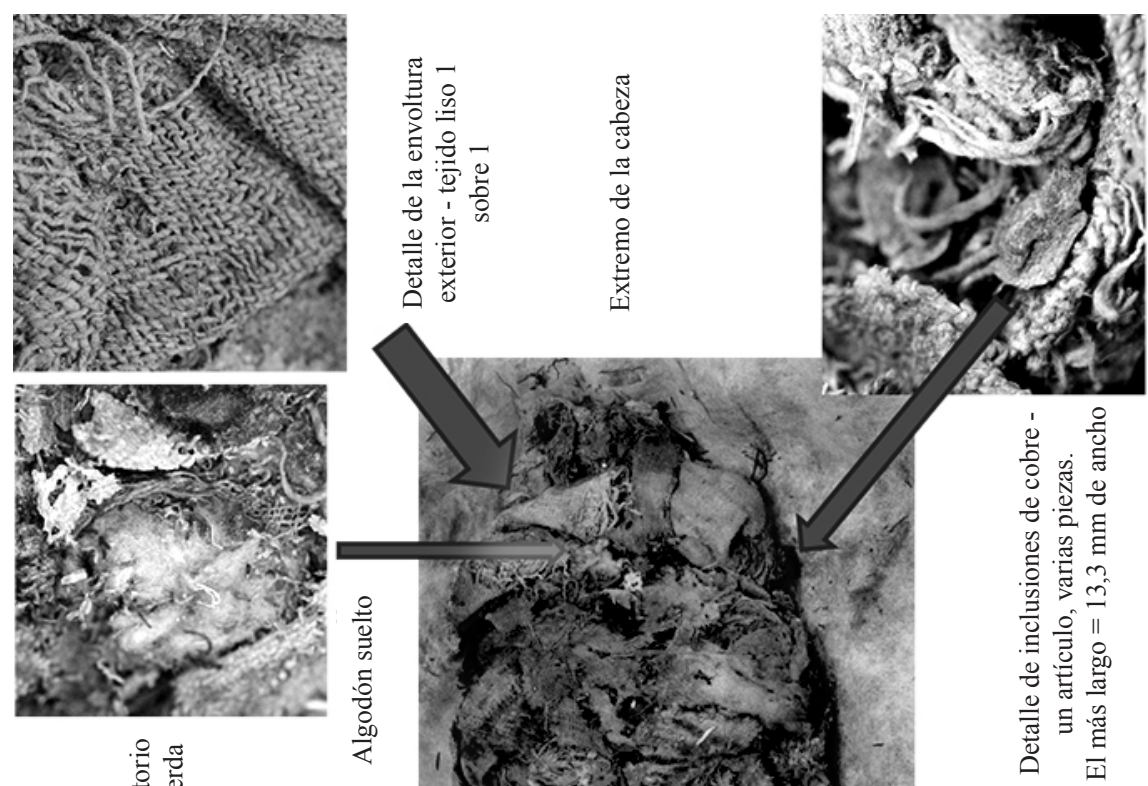

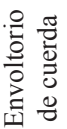
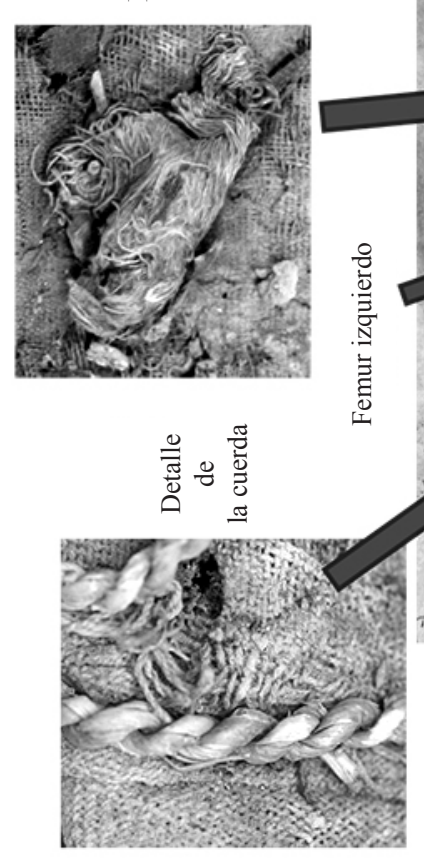

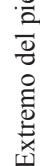

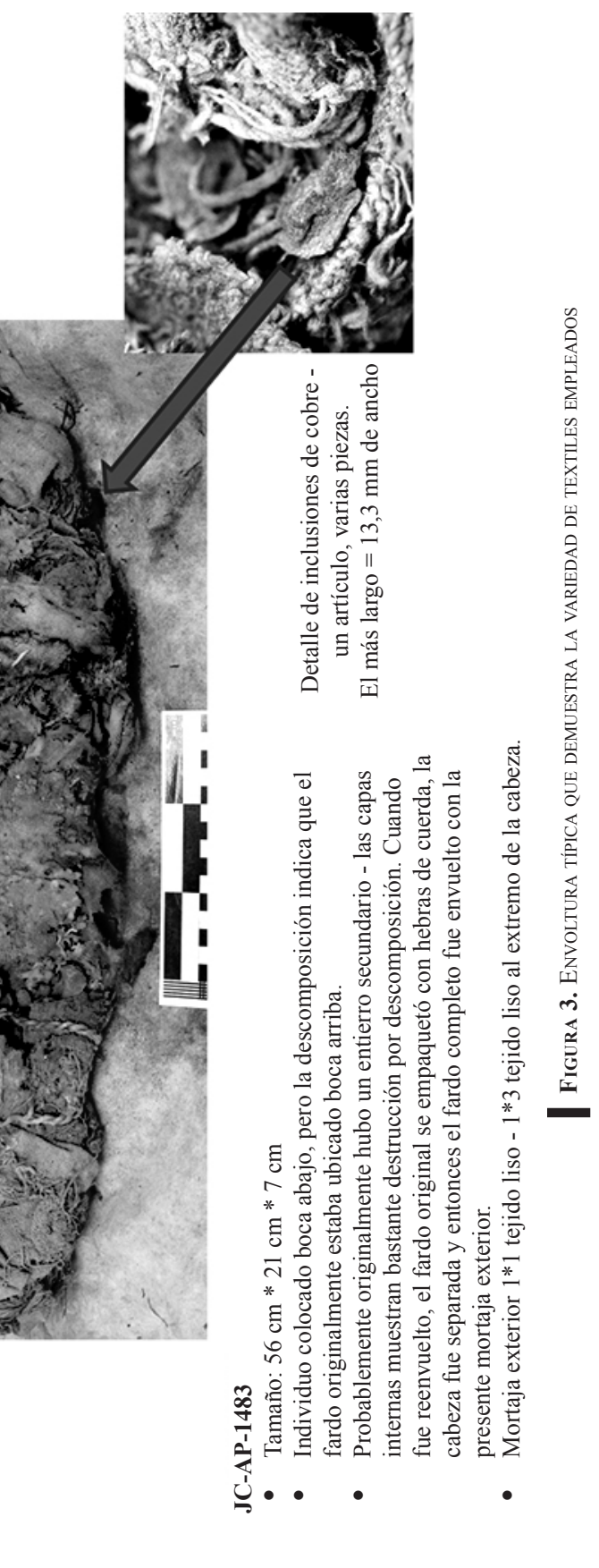




\section{Estado de conservación y estabilidad}

El estado de conservación varió de muy pobre con muchas aberturas en y a través de las diversas capas textiles, a excelentes y muy estables. Las radiografías revelaron restos desarticulados, momificados y esquelétizados en la mayoría de las momias infantiles. La desarticulación entre las momias infantiles no es sorprendente, ya que cuanto más joven es la persona, los sistemas musculo-esqueléticos son menos desarrollados y así como el tejido conjuntivo, lo que favorece la desarticulación. Los huesos del cráneo de las momias infantiles están a menudo desarticulados. Sin embargo, en la mayoría de los casos, el crecimiento de los dientes pudo ser analizado para determinar la edad mediante imágenes radiológicas y endoscópicas. Incluso en los huesos del cráneo desarticulados, intentos de modificación craneal son visibles.
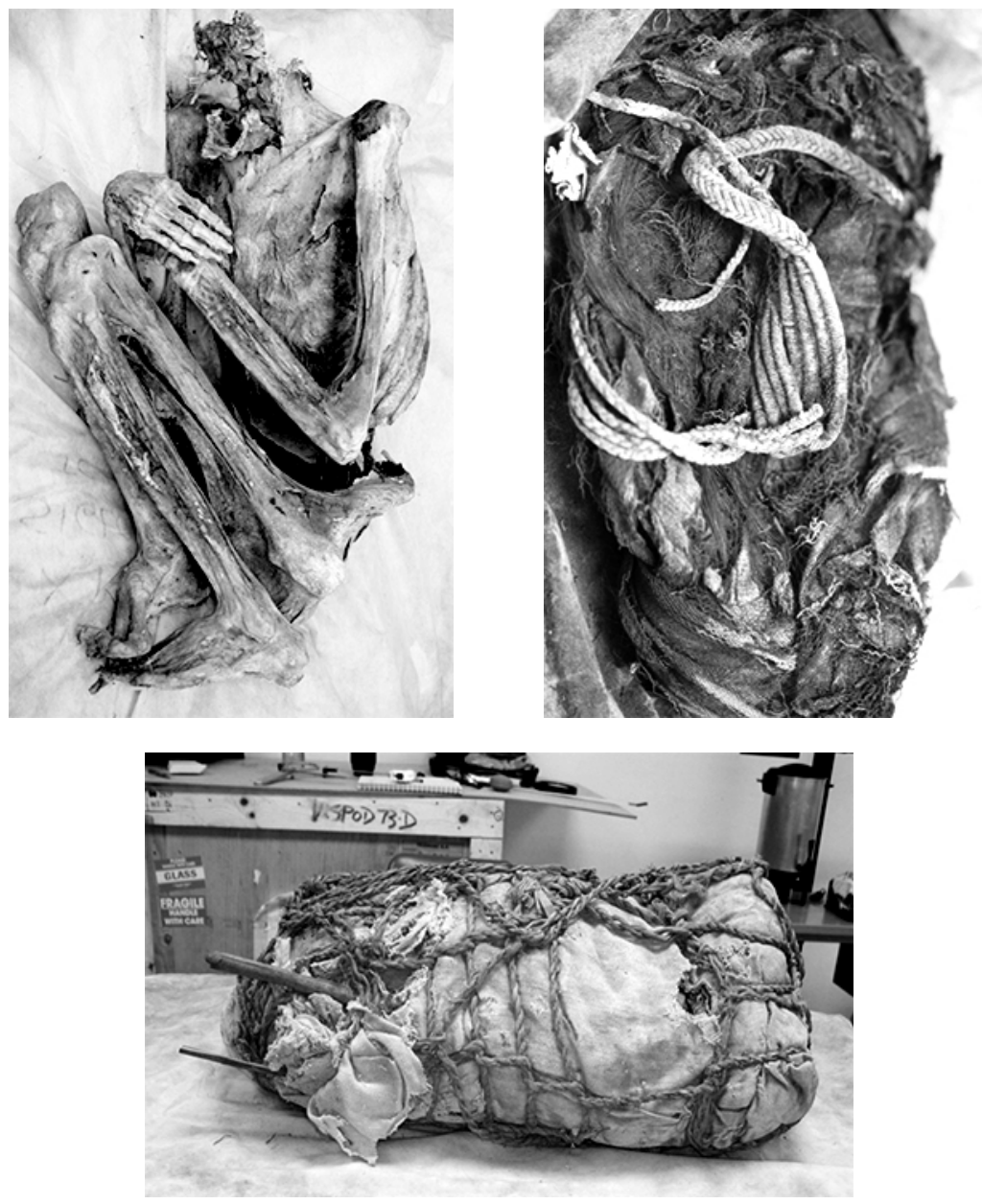

Figura 4. Distintos estados de conservación de los fardos

Los órganos internos se conservan en diversos grados. Algunas de las estructuras de órganos documentados incluyen estructuras pulmonares, e incluso Dura-mater que fue vista en el espacio endo - craneal mediante endoscopia y material cerebral residual. La conservación interior varió entre la muestra, sin embargo, incluso en los lactantes, se encontraron algunos restos de órganos internos. 


\section{Determinación del Sexo}

En la mayoría de los niños y las momias infantiles la determinación del sexo no fue posible debido a la falta de maduración de las características estándar de determinación del sexo del esqueleto. En un bebé, jc - ap - 2064, la determinación del sexo masculino se hizo a partir de la observación directa de los genitales externos.

Entre los adultos $(\mathrm{N}=12) 3$ fueron masculinos, 1 posiblemente masculinos, 5 eran femenino, 1 posiblemente femenino, y 2 no pudieron ser determinados. Las determinaciones se hicieron usando marcadores esqueléticos de las imágenes radiográficas y en algunos casos, por visualización directa.

\section{Modificación craneal}

En el caso de algunas momias infantiles cráneo (jc-ap-1487a) se identifica evidencia de potencial modificación craneal en la radiografía.

\section{Edad al momento de la muerte}

La edad de muerte de los niños y menores se determinó mediante el desarrollo dental y en unos pocos casos $(\mathrm{N}=8)$ a partir de una edad calculada basada en el desarrollo de los huesos largos. Evaluación y estimación de la edad entre las momias adultas incluyen pruebas de estrés (cambios artríticos), superficie articular 'suavizado', y la fusión de las suturas. Los adultos fueron colocados en cuatro categorías, joven, medio, viejo, e indeterminado.

Distribución por edad de las momias de la colección:

\begin{tabular}{|l|c|}
\hline \multicolumn{2}{|c|}{ Menores } \\
\hline Infantes (0-12 meses) & 15 \\
\hline Niños (1-12 años) & 6 \\
\hline \multicolumn{2}{|c|}{ Adultos } \\
\hline Joven & 2 \\
\hline Medio & 2 \\
\hline Viejo & 6 \\
\hline Indeterminado & 2 \\
\hline
\end{tabular}

En función del tamaño de los paquetes no hemos podido examinar otros dos adultos que podrían considerarse dentro de la colección.

\section{Evidencia de enfermedad}

Entre las momias adultas encontramos cambios artríticos leves de las articulaciones de la columna vertebral y de cadera. Además, en la momia jc-ap-2306, descubrimos cartílago traqueal calcificado y anillos bronquiales y una posible aorta descendente calcificada. En una momia infantil cuyos huesos fueron accesibles fuera del paquete, una radiografía reveló múltiples líneas de detención del crecimiento (Harris). Patologías dentales entre los adultos incluyen, fracturas, abscesos, individuos desdentados y desgaste pre-mortem con reabsorción alveolar. 


\section{Evidencia de trauma o lesión}

Encontramos poca evidencia de trauma o lesión en la muestra. En un caso (jc-ap-2064), se encontró una fractura peri-mortem de la tibia izquierda en la radiografía.

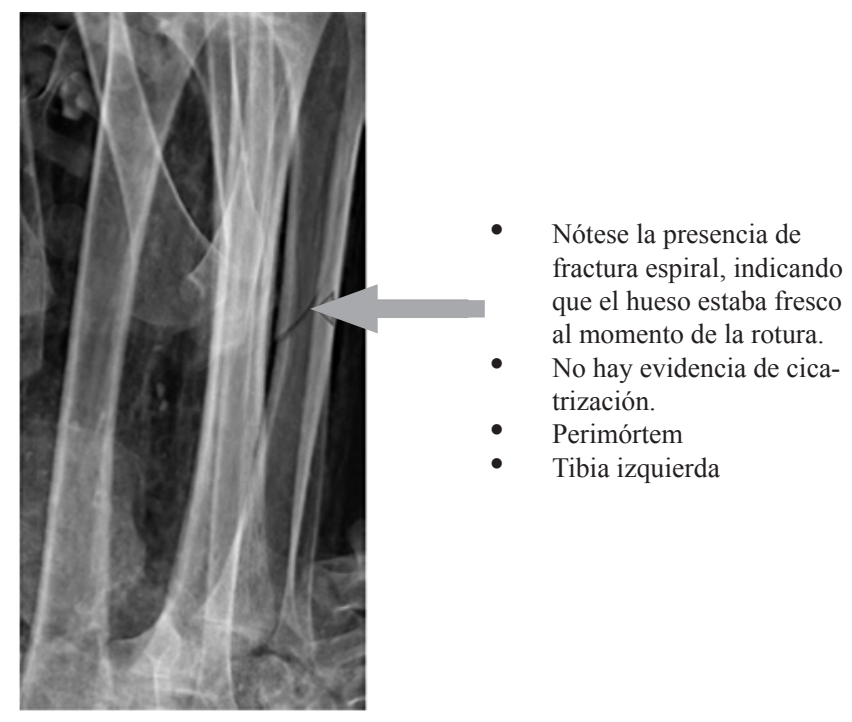

\section{Evidencia de esfuerzos de momificación artificial}

La momificación en este grupo de fardos parece estar hecha por medio de la desecación natural, así como por la actividad de los fluidos corporales en las capas textiles. Se observó evidencia de deterioro de los paquetes aparentemente provocado por los fluidos de la descomposición en varios de los fardos. No se encontraron pruebas de esfuerzos artificiales en la momificación.

\section{Casos seleccionados}

\section{Caso $n^{\circ}$ 1: momia niño je -ap -2064:}

La momia se encontraba en una posición de flexión y se desenvolvió. En varios lugares en el cuerpo se pueden ver Impresiones de la envoltura textil. El estado de conservación es alto, con tegumento conservado que cubre todo el cuerpo con excepción de la región facial.

Evidencia de actividad de insectos presente en todo el cuerpo. El sexo masculino se determinó mediante inspección visual directa de los genitales externos con el escroto y el pene claramente visibles. El análisis radiográfico lateral reveló una momia bien articulado y en conservación con una sola costilla desarticulada. También se nota que fueron desarticuladas la primera y segunda vértebras $(\mathrm{C} 1$ y $\mathrm{C} 2$ ), lo que indica que la cabeza se enterró con los músculos momificados y tegumento del cuello. C1 y $\mathrm{C} 2$ se observaron radiográficamente en la cavidad torácica . Una fractura en la tibia izquierda también se observó en la radiografía, se determinó como peri - mortem ya que no había signos de curación y no hay interrupciones asociadas de la piel adyacente. La edad se determina por el desarrollo dental como se ve en la radiografía, este individuo tiene cerca de 4 años de edad en el momento de la muerte. Análisis endoscópicos se logra haciendo visibles características endocraneales incluyendo 
el cruce de la lambdoidea-suturas sagital, la unión coronal y sagital de sutura sin mostrar la fontanela, el seno venoso, silla turca y ranuras meníngea media izquierda, todos los que muestran anormalidades. La placa cribiforme también fue visto desde el aspecto de la cavidad nasal externa sin anomalías detectadas. El examen endoscópico de la cavidad torácica mostró costillas bien articulados, algunas estructuras de órganos torácicos residuales, así como la $\mathrm{C} 1$ y C2 desarticuladas. Los dientes fueron vistos a través de la endoscopia de la cara lingual y no se encontraron anomalías. Si bien la causa de la muerte no se pudo determinar con certeza, patologías intestinales o pulmonares serían los probables sospechosos. Estos pueden producir una enfermedad aguda que no tendría tiempo para salir de cambios óseos. Es de destacar que, debido a la superposición de las sombras en la radiografía, el crecimiento de líneas de detención de Harris no podía ser visto.

\section{Caso $n^{\circ}$ 2: momia niño jc -ap -1487:}

La momia estuvo probablemente en una posición extendida, dado que la mayoría de los huesos largos asociados se habían soltado y fueron envasados por separado. El paquete es un buen ejemplo de la complejidad de las prácticas funerarias. El paquete incluye dos capas textiles, uno un tejido liso en los pies y el cuerpo, y el otro un azul marrón estampado de rayas en la cabeza. Una calabaza estaba dentro de la envoltura justo debajo de la mandíbula aunque era difícil de ver en las radiografías.

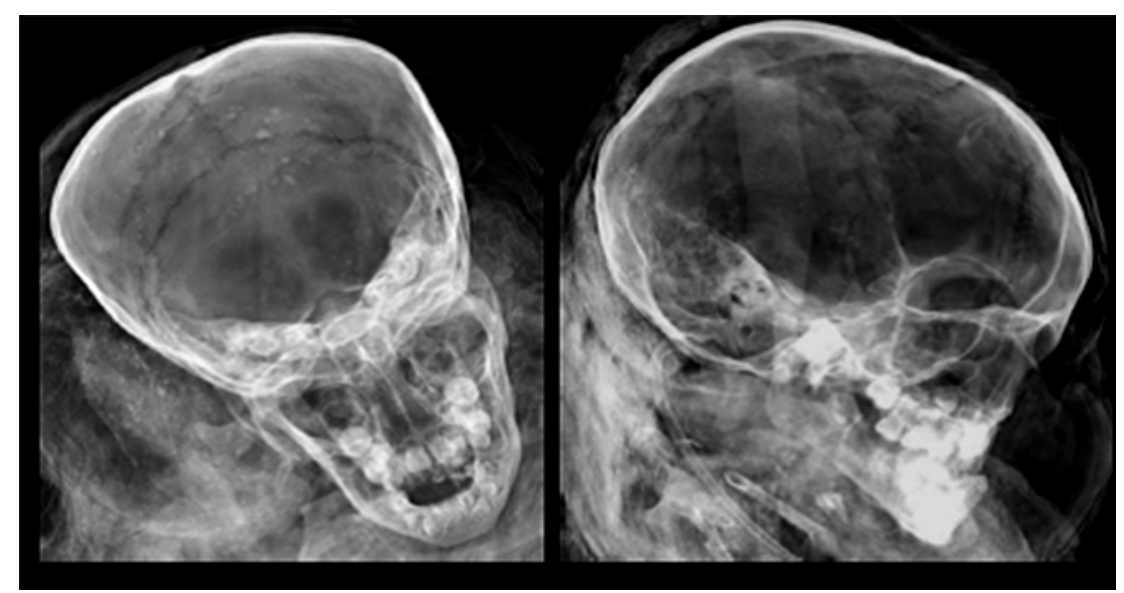

Además, no había una construcción elaborada de una cuna hecha de bambú y poste de madera. Esteras y cuerdas también fueron incorporados en el diseño del paquete. El paquete mide $72 \mathrm{~cm}$. X $28 \mathrm{~cm}$. X $22 \mathrm{~cm}$. Un tercer textil, un ovillo de hilo o cordel se observó entre la matriz a mitad de camino en el lado derecho. La estimación de la edad se realizó utilizando mediciones de los huesos largos y los patrones de erupción dental sugieren que este niño era de alrededor de 5 años de edad en el momento de la muerte. Varias proyecciones radiográficas mostraron las variadas densidades de los materiales de cuna incluyendo los postes de madera, bambú y esteras de junco. Las radiografías también proporcionaron puntos de vista de la dentición que contribuye a la estimación de la edad. La ausencia de los huesos largos dentro del haz se confirmó con la radiografía.

El análisis radiográfico de los huesos largos asociados mostró muchas líneas de crecimiento de detención de Harris que indican que el niño experimentó una enfermedad estacional a lo largo de la vida, en la medida en que el crecimiento se ha detenido temporalmente. Análisis endoscópicos proporcionan imágenes de la calabaza y de su posición debajo de la mandíbula. 


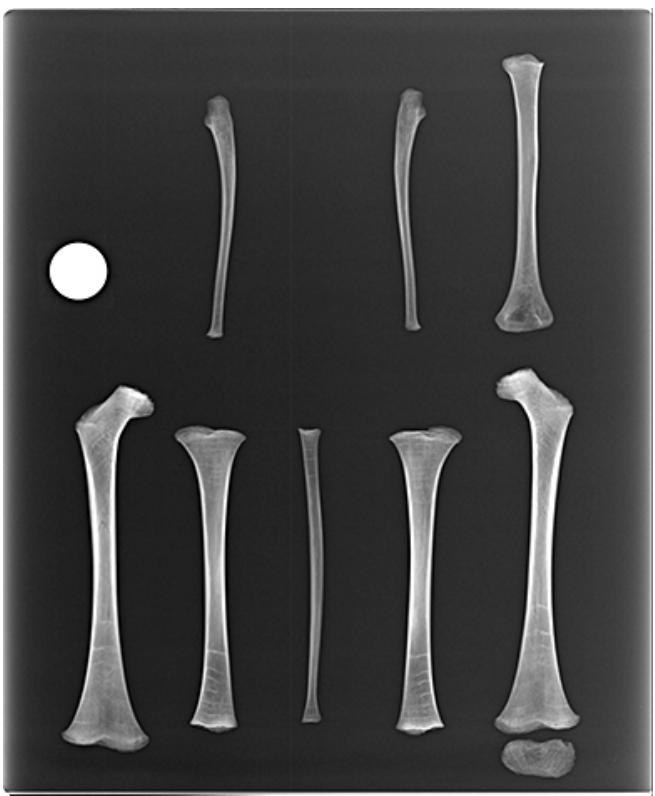

La endoscopia también reveló varias características endocraneales incluidos los huesos wormianos, surcos meníngeos, suturas separadas y escombros residuales dentro de la bóveda endocraneal. Las imágenes endoscópicas proporcionaron documentación adicional del patrón de erupción dental que contribuyen a la estimación de la edad. Si bien la causa de la muerte no se pudo determinar con certeza, dado que este niño sufrió periodos frecuentes de enfermedad grave, como lo demuestra el crecimiento de líneas de detención de la Harris, lo más probable es que murió de una enfermedad gastrointestinal o pulmonar aguda.

\section{Caso $n^{\circ}$ 3: momia adulta femenina jc -ap -2306:}

La momia se encontraba en una posición flexionada y el entierro se habia ya desenvuelto en el momento de nuestro análisis. La cabeza fue desarticulada del cuerpo con las dos cuencas de los ojos llenos de algodón. Tanto el cuerpo como la cabeza estaban razonablemente bien conservados. El sexo de la momia fue determinado por varias características morfológicas incluyendo marcadores óseos craneales y pélvicos. Datos radiográficos incluyen la documentación de un individuo esencialmente desdentado pre y post mortem. Se observó resorción alveolar. La radiografía mostró poco o nada de artritis de la columna, las articulaciones de la cadera leves escleróticas y una posible aorta descendente calcificada. La radiografía también reveló traquea calcificada y principales anillos bronquiales. Debido a la inestabilidad en la región lumbar no se obtuvo una proyección anterior-posterior.

La endoscopia complementa las imágenes radiográficas que revelan la presencia de estructuras pulmonares incluyendo la tráquea y los pulmones. Además, las imágenes del endoscopio revelaron una adhesión pulmonar probable cerca o en el ápice derecho que indica una infección reciente o activa en la periferia de los pulmones. La vía aérea superior se conserva muy bien con las cuerdas vocales que se visualizan dentro de la laringe. Endoscopia de la bóveda craneal reveló unos pocos restos del cerebro, así como una considerable duramadre.

Aunque el individuo era desdentado, la falta de cambios artríticos sugiere un adulto de edad media. Teniendo en cuenta las calcificaciones de la tráquea y los anillos bronquiales y la posible aorta descendente calcificada, esta mujer se colocó en la categoría de adultos viejos en el momento de la muerte. Un tatuaje o patrón se observó en la muñeca izquierda y fue fotografiado bajo la luz natural y alternativa. El significado de los tatuajes no se determinó.

La causa de muerte es indeterminada. Los anillos traqueales y bronquiales calcificadas tienen varias etitologias posibles incluyendo la edad avanzada, osteoplastia tracheapathia, granulomatosis de Wegener, y el uso prolongado de sustancias anti- coagulantes. La presencia 
de una adhesión pulmonar sugiere una infección pulmonar activa o reciente en o cerca del momento de la muerte.

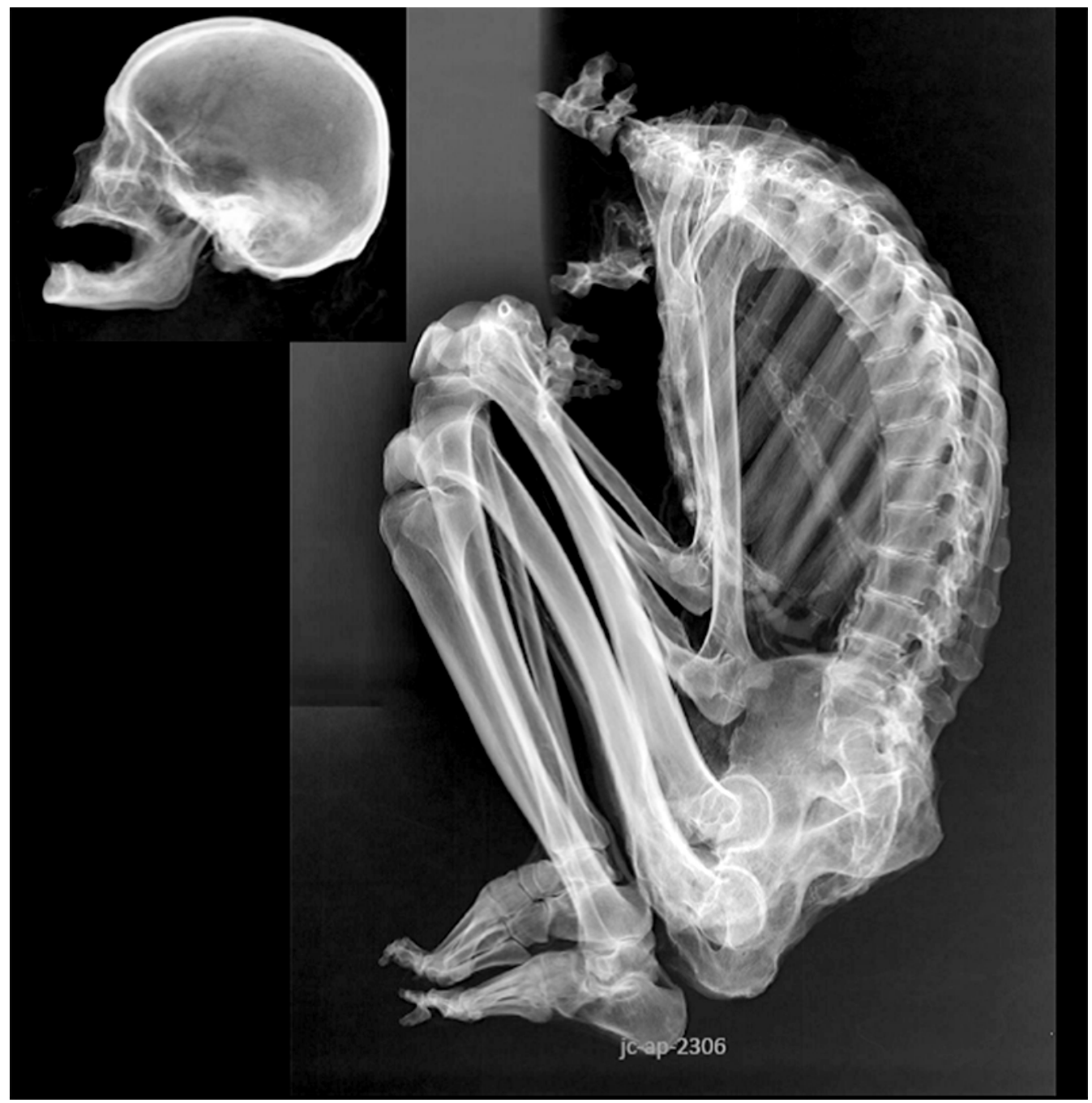

Caso $n^{\circ}$ 4: artefacto Inclusiones jc -ap -1476:

Este breve caso demuestra ejemplos de inclusiones de artefactos. El paquete era de aproximadamente $72 \mathrm{~cm}$ de longitud y fue apretujado y atado. Varias capas de textiles se utilizaron para rodear los restos y se aseguraron los textiles con cuerdas finas. Embalaje de algodón fue evidente en la inspección visual. Una imagen compuesta de la radiografía antero-posterior mostró una momia infantil desarticulada con varios postes de madera integrados. La estimación de la edad calculada para este niño era de unos 9 meses en el momento de la muerte. El paquete estaba apretujado con algodón. También son visibles en la radiografía varios artefactos. Motas metálicas, probablemente de joyería de algún tipo; Justo debajo de la mandíbula se identifica un artefacto en forma de "pájaro". Un artefacto metálico grande está presente y tiene la forma de un conjunto de pinzas o una herramienta de tipo pinza utilizada para el afeitado. 
Dado que este bebé no es claramente de la edad para ser afeitado, este artefacto puede sugerir que se trataba de un bebé varón y que se necesitarían las pinzas en algún punto más allá de su entierro. En la parte superior del cráneo, opacidades débiles que se corresponden con formas de conchas o caracoles también son descritas.

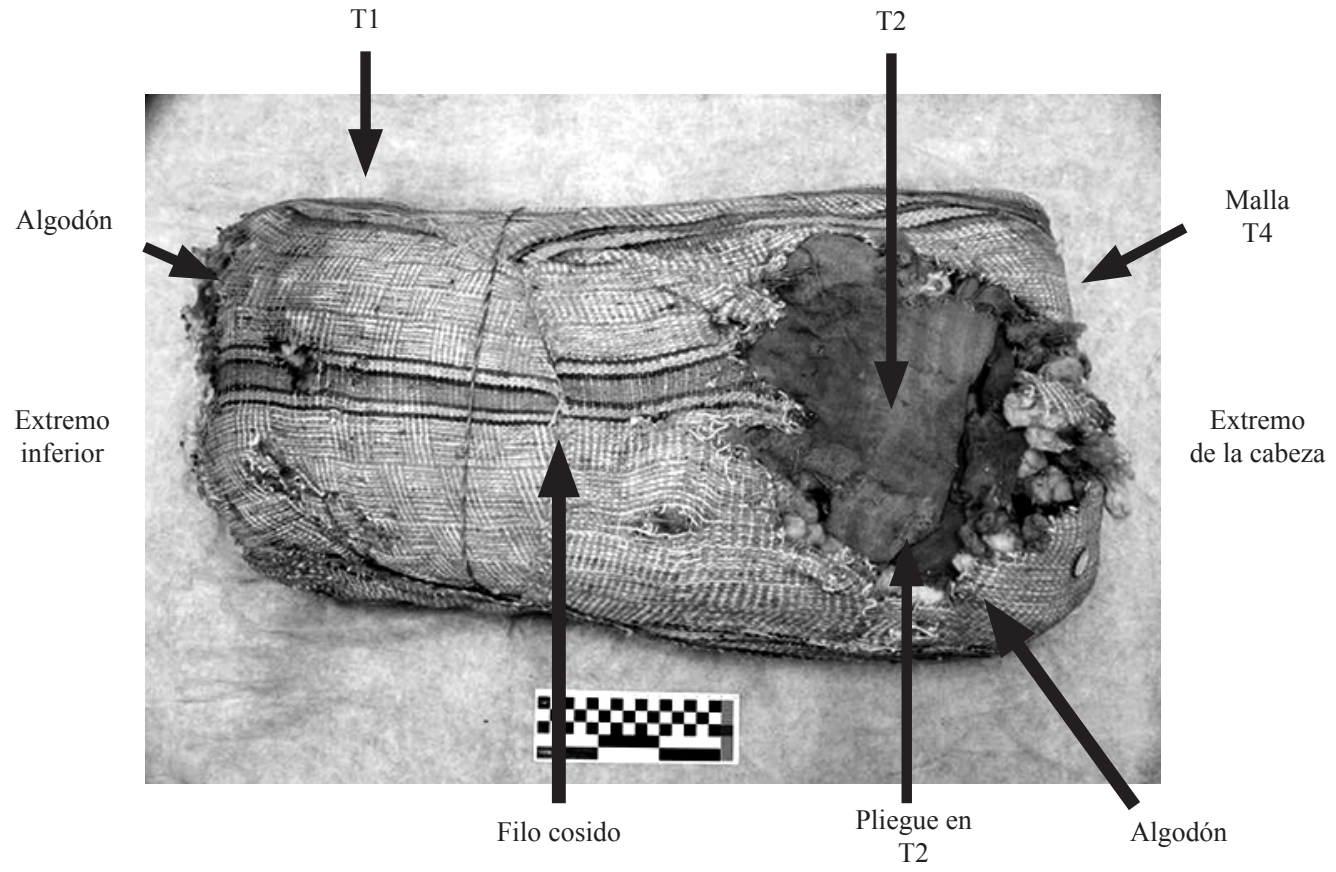

JC-AP-1476

- Fardo $=69 \mathrm{~cm} * 34 \mathrm{~cm} * 24 \mathrm{~cm}$

- Neonato de ca. 9 meses

- Posición extendida (piernas flexionadas - post mortem?)

- 4 varas de cañas incluidas

- Nótese la presencia de artefactos de metal en la barbilla

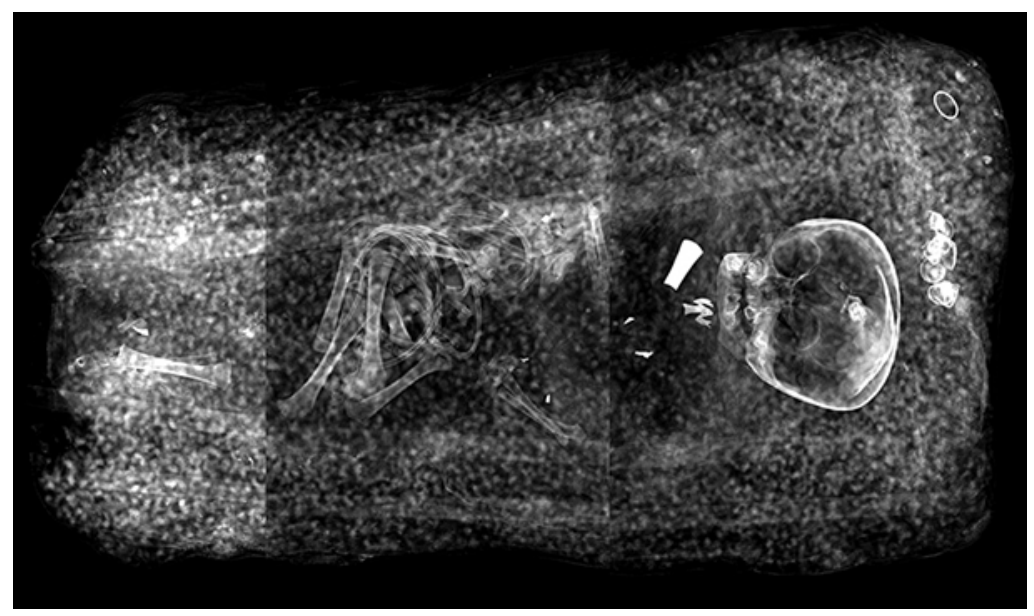




\section{Caso $\mathrm{n}^{\circ}$ 5: momia femenina adulta jc-ap-2288:}

En este caso se trata de una mujer adulta mayor, en las radiografías vemos la artritis lumbar, condición dental extremadamente pobre incluyendo perdida pre mortem y desgaste excesivo del esmalte. Durante la endoscopia, se observó una masa intratorácica general, así como los huevos de arácnidos y varios nidos de arácnidos. Además, intrusiones tipo clavos fueron vistos en la rodilla derecha y el otro cerca de la vértebra lumbar inferior.

\section{Discusión}

La importancia de esta expedición se basa en la exploración y documentación a través de análisis no destructivo de esta población de momias preincaicas de la que poco se sabe. La investigación llevó al campo (ubicación dentro del museo) instrumentación sofisticada no destructiva para Paleoimagen, lo que minimiza el movimiento de los fardos y los posibles riesgos asociados. Los resultados de este estudio se suman considerablemente a nuestra comprensión bioarqueológica de la vida de los ocupantes de Maranga. Las momias, aunque muy bien conservada, está en riesgo de deterioro continuo simplemente por el paso del tiempo, la información derivada de este estudio ha impedido la pérdida de datos importantes en relación con este grupo y nos ha dado una rara visión de la vida de estos individuos y en cierta medida de la forma en que interactuaban con su entorno. Basándose en los resultados de este estudio se sugieren varias características importantes respecto a las prácticas funerarias y población representadas en la colección.

En primer lugar, en la colección existen más bebés y niños (67\%) en comparación con los adultos. Hay probablemente varias explicaciones para esto. El sitio de entierro en particular desde donde se excavaron estos paquetes puede haber favorecido entierros lactantes y de niños pequeños. Además, cuando se considera el transporte de los fardos desde Perú a Ecuador, Caamaño pudo haber seleccionado los que serían más fáciles de empacar, favoreciendo así los paquetes más pequeños y, cuando era posible, incluyendo varios paquetes adultos también.

La presencia de numerosos enterramientos infantiles es consistente con las tasas de mortalidad infantil que se ha demostrado en muchas culturas precolombinas. La muestra ofrece al menos una momia infantil que muestra evidencia de enfermedad periódica repetida en forma de líneas de detención del crecimiento de los huesos largos (véase el caso $\mathrm{N}^{\circ} 2$ ).

Un resultado sorprendente fue la falta de cambios artríticos significativos entre las momias adultas de la población estudiada. Esto puede sugerir que los adultos de este grupo eran de un estrato social algo más elevado, con menos convocatoria a tareas laboriosas, reduciendo así el desgaste de las articulaciones individuales. La momia que presenta una muñeca tatuada es única entre esta colección y puede apoyar la construcción de un estatus social más alto. Sin embargo, es difícil especular sobre la condición social sin pruebas adicionales.

Tampoco es fácil de explicar la falta de cambios artríticos significativos. Con esto dicho hay amplia evidencia de enfermedades asociadas con la edad avanzada incluyendo afecciones dentales, así como patologías pulmonares aparentes.

Otro resultado interesante fue la falta de episodios traumáticos, ya sea pre o peri mortem, entre los individuos de la colección. Esto puede apoyar aún más la premisa de estratos sociales más altos o de un grupo protegido de las personas. La baja incidencia de lesiones traumáticas también puede explicarse por la estructura social avanzada atribuida a los sistemas de canales expandidos diseñados para garantizar la distribución equitativa del agua entre los barrios y pueblos de los Maranga. Si existía una estructura social equitativa, se puede suponer que un estilo de vida más pacífica estuvo presente, dando lugar a una incidencia de trauma menor.

Tal vez uno de los hallazgos más importantes de este estudio fue el cuidado y detalle en preparación de los muertos para el más allá. Entre esta muestra encontramos amplia evidencia de la atención detallada en las prácticas funerarias, asegurando la comodidad y seguridad de 
la persona fallecida. El volumen de algodón utilizado, el proceso de agrupación meticuloso y complejo usando varios tejidos, llevando cunas de madera, bambú y esteras de junco, dan fe de un proceso de cuidar al individuo en la transición de la vida a la muerte. Además, la inclusión de artefactos incluyendo adornos, alimentos y elementos prácticos necesarios en la vida (véase el caso $\mathrm{N}^{\circ} 4$ ), todos sugieren un aire de compasión y dedicación a la hora del entierro, incluso en los individuos más jóvenes.

En resumen, la muestra representa los cambios observados en el tiempo con respecto a las prácticas funerarias de Maranga. La variación en el estilo y la configuración de los fardos visto en este estudio sugieren "variaciones sobre un tema" relacionados con las preocupaciones de entierro culturales. Este estudio nos ha proporcionado una mejor comprensión del contexto bioarqueológico de esta colección y las cultura que ocuparon Maranga y su lugar en la antropología de la antigua América del Sur. Aunque no se descubrieron medios artificiales de momificación, las prácticas funerarias y de entierro de la Maranga sugieren un grado alto de preparación de los individuos previo a su depósito dentro de las Huacas.

Este estudio contribuye al creciente cuerpo de conocimiento sobre poblaciones indígenas pre -incas y ofrece un enfoque metodológico para paleoimagen en el lugar de campo de investigación bioarqueológico. Las imágenes producidas a través de esta investigación se pueden usar como comparaciones y la posterior identificación de otros grupos donde aún no se han identificado restos culturales y artefactos.

\section{Agradecimientos:}

National Geographic Expeditions Council

O’Shannon Burns, National Geographic

Prof. José María Jaramillo- Director Museo JJC

Oscar Manosalvas- Curador área de arqueología Museo JJC

Personal del Museo Jacinto Jijón y Caamaño

Centro Cultural de la Pontifica Universidad Catolica del Ecuador

Michael J. Wright, Fotografo.

Katherine J. Harper-Beckett, Videografa.

Soledad Alvarez and Mario Ordoñez

Dr. Fernando Haro - Jefe de servicios Hospital AXXIS

Dr. Edison Chaves Almeida- Decano de la Facultad de Medicina PUCE

Dr. Wagner Narango- Patólogo PUCE

Vanesa Paladino- tecnóloga de Tomografias Hospital AXXIS 


\section{Bibliografía}

Alegre, G. O. 2014, “Tejidos de la cultura Lima hallados en las huacas de Pando, valle del Rimac", en: Boletín IRA, (25), pp: 285-324.

Cornejo, M., \& Cornejo, M. A. 1992, "Cronología y costumbres sepulcrales en Lauri, valle de Chancay”, en: Estudios de Arqueología Peruana, pp: 311-354.

Desrosiers, S. 2014, Highland Complementary-Warp Weaving and the Lima Style in the Central Coast of Peru, ca. 200-650 CE.

Eeckhout, P. 2004, "La sombra de Ychsma. Ensayo introductorio sobre la arqueología de la costa central del Perú en los períodos tardíos", en: Bulletin de l'Institut français d'études andines, (33 (3)), pp: 403-423.

Evans, C. 1956, Proto-Lima: A Middle Period Culture of Peru. AL Kroeber. American Anthropologist, 58(1), 204-205.

Fernández Sotomayor, J. 1959, “El estilo Maranga: apuntes preliminares para su estudio y clasificación. Antiguo Perú: espacio y tiempo", en: Semana de arqueología peruana. Lima, 9-14 Nov. 1959;

Jijón, J. 1949, Maranga: contribución al conocimiento de los aborígenes del Valle del Rimac, Perú. La Prensa Católica,.

Kroeber, A. L., \& Wallace, D. T. (1954). Proto-Lima: a middle period culture of Peru. Fieldiana. Anthropology, 1-157.

Lumbreras, Luis G. 2010, Jacinto Jijón y Caamaño. Estudios sobre Lima Prehispánica: Maranga, FONSAL. Quito.

Stumer, L. M. 1954, "Population centers of the Rimac Valley of Peru” en: American Antiquity, pp: $130-148$.

Svendsen, T. P. 2010, Arqueología en el Perú: nuevos aportes para el estudio de las sociedades andinas prehispánicas, Universidad Nacional Federico Villarreal.

Tello, C. Jaime. 2014, "Investigaciones en la Huaca de San Marcos”, en: Investigaciones Sociales, 3(3), pp: 65-91. 